Copyright by the Ecological Society of America (ESA). Rebecca E. Irwin, Lynn S. Adler, and Alison K. Brody 2004 . THE DUAL ROLE OF FLORAL TRAITS: POLLINATOR ATTRACTION AND PLANT DEFENSE. Ecology 85:1503-1511. http://dx.doi.org/10.1890/03-0390

\title{
THE DUAL ROLE OF FLORAL TRAITS: POLLINATOR ATTRACTION AND PLANT DEFENSE
}

\author{
Rebecca E. Irwin, ${ }^{1,2,5}$ Lynn S. Adler, ${ }^{3}$ AND Alison K. Brody ${ }^{2,4}$ \\ ${ }^{1}$ Institute of Ecology, University of Georgia, Athens, Georgia 30602 USA \\ ${ }^{2}$ Rocky Mountain Biological Laboratory, Crested Butte, Colorado 81224 USA \\ ${ }^{3}$ Department of Biology, Virginia Tech, Blacksburg, Virginia 24060 USA \\ ${ }^{4}$ Department of Biology, University of Vermont, Burlington, Vermont 05405 USA
}

\begin{abstract}
Plants are under siege from a diversity of enemies that consume both leaf and floral parts. Plants resist damage to leaves in a variety of ways, and we now have a rich literature documenting how plants defend themselves against herbivore attack. In contrast, the mechanisms by which plants resist enemies that consume floral parts or resources are much less known, even though damage to floral tissue usually has tighter links to plant fitness than damage to leaf tissue. Many plants experience nectar robbing, whereby floral visitors remove nectar from flowers, often without pollinating. Nectar robbers can reduce plant fitness to degrees comparable to, or even surpassing, reduction by herbivores. However, because nectar attracts both pollinators and nectar robbers, plants face a dilemma in defending against nectar robbers without also deterring pollinators. Here, we extend the conceptual framework of resistance to herbivores to include resistance to nectar robbers, focusing on nectar traits. We review published data and find that an array of nectar traits may deter robbers without deterring pollinators. Although resistance traits against robbers have been broadly identified, the costs and benefits of these traits in terms of plant fitness remain poorly understood. We present data showing that a nectar trait (dilute nectar) might directly, as well as indirectly, benefit plant fitness by deterring nectar-robbing bumble bees of Ipomopsis aggregata without deterring hummingbird pollinators. However, the magnitude of any plant fitness benefit will depend on the degree to which plants are pollen- vs. resource-limited in a given year. The results of our work offer both conceptual and empirical insight into how plants cope with attack by nonpollinating floral visitors through a relatively unexplored trait, nectar.
\end{abstract}

Key words: Bombus occidentalis; bumble bee; herbivory; Ipomopsis aggregata; nectar concentration; nectar robbing; plant defense; pollination; resistance.

\section{INTRODUCTION}

Plants are attacked by a variety of organisms that feed in different ways and on different types of tissue. At any given time, a plant may face damage by herbivores feeding on leaves or flowers, while others feed on roots, and still others consume sap, phloem, or xylem. The defenses deployed against such enemies can be constitutive or induced (Bryant et al. 1988, Karban and Meyers 1989). The defenses can be quite general and effective against many organisms (Krischik et al. 1991, Omer et al. 2001), or highly specific and effective against a single type or species of herbivore (Agrawal and Karban 2000). By mounting defenses against enemies, plants increase their resistance to further feeding and, presumably, minimize the fitness costs of damage (Karban and Myers 1989).

Resistance is the ability of plants to decrease the frequency of attack (Painter 1958). The ability of plants

Manuscript received 9 June 2003; revised 2 September 2003; accepted 8 September 2003. Corresponding Editor: A. A. Agrawal. For reprints of this Special Feature, see footnote 1, p. 1477.

5 Address for correspondence: Institute of Ecology, Ecology Building, University of Georgia, Athens, Georgia 30602 USA. E-mail: rirwin@uga.edu to resist enemy attack may be more difficult when mutualists and antagonists use the same resource, such as nectar. Organisms that feed on nectar without providing pollination service in return (henceforth referred to as "nectar robbers" or "nectar thieves") can have substantial effects on male and female plant fitness (reviewed in Irwin et al. 2001). A meta-analysis of existing studies suggests that floral larceny has an overall detrimental effect on female plant reproduction (Irwin et al. 2001), although individual studies find that nectar robbing can have a continuum of effects on plant reproduction, from positive to neutral to negative (Maloof and Inouye 2000). Nectar robbers can reduce plant fitness to degrees comparable to, or even surpassing, fitness reduction by herbivores (Juenger and Bergelson 1997, Irwin and Brody 2000). Damage to floral tissue can have stronger links to plant fitness than does damage to leaf tissue (reviewed in Strauss et al. 2003); nectar robbing can reduce female fitness by $50 \%$ (e.g., Irwin and Brody 2000, Lara and Ornelas 2001) and estimates of male fitness by up to $80 \%$ (Irwin and Brody 1999). Yet, the mechanisms by which plants resist nectar robbers are less well known than mechanisms associated with resistance to herbivores. This lack of

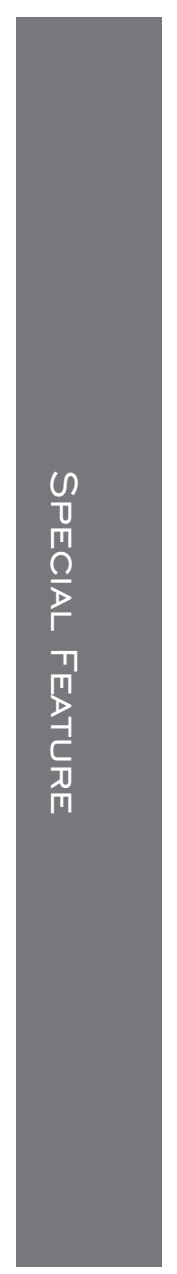


understanding is surprising for a number of reasons. First, nectar robbing is extremely common among flowering plants (Irwin and Maloof 2002). Most plant species with tubular corollas or flowers with nectar spurs experience some form of floral larceny. Moreover, the mechanisms by which nectar robbers affect plant fitness are analogous to those of herbivores. These include direct mechanisms, such as damage to floral reproductive organs (Galen 1983, Adler et al. 2001), as well as indirect mechanisms, such as changes in pollinator behavior (Strauss et al. 1996, Irwin and Brody 2000). Concepts of resistance have been applied to other antagonistic interactions besides herbivory, such as predation, providing a unifying theory across taxa (e.g., Agrawal et al. 1999, Brönmark et al. 1999). Therefore, it seems likely that the concept of resistance can be applied to understand how plants cope with nectar robbers in cases in which robbers negatively affect plant fitness.

Resistance to nectar robbing, however, presents plants with a conundrum not experienced in preventing attack by leaf-feeding herbivores. The nature of this quandary lies in providing nectar as a reward for mutualist pollinators. Pollinator attraction is critical to the reproductive success of the majority of flowering plants (reviewed in Kearns et al. 1998). However, the payment for attracting pollinators can be costly, both in the amount of resources invested (Pyke 1991) and in attracting nectar robbers. Thus, how might plants attract pollinators while avoiding nectar robbers?

The aim of this contribution is to extend the existing conceptual framework of resistance to herbivores to include nectar robbers. We review the literature on resistance to robbers, highlighting the subtle but important similarities between resistance to herbivores and robbers. We then present new data and suggest future areas of research in this field. Although this work is focused on resistance to nectar robbers, the predictions and results presented are applicable and functionally similar to other plant-animal interactions in which plants face trade-offs in attracting mutualists and antagonists, such as plant interactions with seed dispersers and seed predators (Herrera 1982, Cipollini and Levey 1997).

\section{Resistance to Nectar Robbing}

There are striking similarities between mechanisms associated with resistance to herbivores and resistance to nectar robbers. As with herbivores, resistance to nectar robbers can involve (1) toxins and chemical deterrents, (2) escape in time, (3) escape in space, (4) physical barriers, and (5) indirect resistance. Some of these traits can confer resistance to floral larcenists without deterring pollinators. Hereafter, we define nectar robbers as those organisms that remove nectar through holes bitten in flowers, often without pollinating. Nectar thieves remove nectar through the floral opening used by legitimate pollinators but do not contact the sexual organs of flowers (Inouye 1980). For simplicity, we include all floral larcenists (both nectar robbers and thieves) under the term "nectar robber" except in cases in which we describe scenarios only applicable to nectar thieves.

Although one might ascribe adaptive function to traits that deter nectar robbers, it is likely that many, if not most, of the resistance traits against robbers that we will describe are exaptations (Armbruster 1997) and thus did not evolve in response to selection by robbers, per se. Traits that confer resistance to robbers most likely represent traits involved in one set of interactions (interactions between plants and pollinators or interactions between plants and herbivores) that have been co-opted into other, very different interactions. Many of these traits may also reflect pleiotropic effects between traits that confer resistance to herbivores and resistance to nectar robbers.

\section{Toxins and chemical deterrents}

Plant compounds associated with herbivore resistance (secondary compounds or toxins) are surprisingly common in floral nectar (Baker 1977, Adler 2000). Although the benefits of "toxic nectar" are debated (Adler 2000), a few examples suggest that toxic nectar may reduce the frequency of nectar robbing. In Catalpa speciosa, nectar containing iridoid glycosides deterred nectar-thieving ants but did not deter legitimate bee pollinators (Stephenson 1981, 1982). In Gelsemium sempervirens, experimental manipulation of alkaloids in nectar deterred nectar-robbing carpenter bees, but at a cost of reduced visitation by legitimate bee pollinators (L. S. Adler and R. E. Irwin, unpublished manuscript). Petal tissue can also contain secondary compounds (Euler and Baldwin 1996). Guerrant and Fiedler (1981) suggest that corolla-tube damage by ants on a variety of tropical species can release secondary compounds from petal tissue into the nectar. Secondary compounds thus released may serve to protect the plants from nectar-robbing or nectar-thieving ants, although this has never been explicitly tested. These studies demonstrate that secondary compounds may deter robbers; however, the benefits of toxic nectar will depend on the degree to which the toxins also affect pollinators and, ultimately, plant fitness.

Sugar and other more minor nectar components may also affect the frequency of nectar robbing. For example, the flowers of Lathraea clandestina produce nectar with a high $\mathrm{pH}$ due to the presence of dissolved ammonia. Dissolved ammonia is tolerable to bumble bee pollinators but is hypothesized to deter nectarthieving ants (Prŷs-Jones and Willmer 1992). Some floral visitors prefer nectar with specific amino acid components or concentrations (Gardener and Gillman 2002). Although unexplored, such variation in preference implies that nectar composition could deter some nectar-robbing taxa while luring some pollinator taxa, or vice versa. Low sugar concentration in nectar 
may deter nectar-robbing bees without deterring some pollinators. Bolten and Feinsinger (1978) argue that dilute nectar does not yield net energy profits for some nectar-robbing bees. However, dilute nectar with low viscosity might not deter some legitimate pollinators, such as hummingbirds, that feed by capillary action (Baker and Baker 1982; but see Pyke and Waser 1981, Martínez del Rio et al. 2001). As far as we know, this hypothesis has never been explicitly tested.

\section{Escape in time}

Just as plants can escape herbivore damage by leafing out when herbivores are absent or rare (Feeny 1970), plants can avoid damage from nectar robbers by varying their timing of nectar production or flowering (Irwin et al. 2001). For example, if nectar robbers and pollinators are active at different times of day, plants may benefit by producing nectar on a diel rhythm that coincides with peak pollinator activity and relative inactivity of robbers. Hummingbird pollinators forage most actively in the morning and late afternoon on Castilleja linariaefolia, times when nectar-robbing carpenter bees are relatively inactive due to cool temperatures (Carpenter 1979). Although C. linariaefolia produces nectar all day, peak rates of nectar production occur in the morning and late afternoon, coinciding with peak pollinator visitation and low nectar-robber visitation (Carpenter 1979).

\section{Escape in space}

Plants may also escape nectar robbers by growing next to host plants that are more preferable to robbers, loosely analogous to associational resistance to herbivores (Tahvanainen and Root 1972). The most compelling evidence thus far for associational resistance to robbers comes from Ipomopsis aggregata (scarlet gilia), which is robbed by Bombus occidentalis (Irwin and Brody 1998). Where I. aggregata co-occurs with Linaria vulgaris, a species introduced to the Colorado Rocky Mountains over 100 years ago, robbing rates to I. aggregata are $68 \%$ lower than in areas where $L$. vulgaris does not occur. Bombus occidentalis prefers L. vulgaris, which receives $60 \%$ more robbing than $I$. aggregata where the two species grow together. Thus, L. vulgaris provides associational resistance to $I$. aggregata by luring away robbers, resulting in decreased robbing and increased seed set of I. aggregata where the two species co-occur (Irwin et al. 2001).

\section{Physical barriers}

Physical barriers, such as thick leaves, thorns, and trichomes, are effective at deterring herbivores. Similarly, a variety of physical traits may confer resistance to nectar robbers without deterring pollinators. Tightly packed flowers may physically deny nectar robbers access to nectar spurs or the sides of corolla tubes (Proctor et al. 1996). Short corolla tubes may decrease the frequency of robbing by some hummingbirds (Lara and
Ornelas 2001). Bract liquid that can create a "moat" around flowers may prevent nectar-robbing ants from gaining access to nectar (Wootton and Sun 1989). Finally, the toughness of the corolla or calyx may make it difficult for robbers to chew holes. For example, in central Panama, it takes solitary workers of the bee Trigona ferricauda $\geq 30 \mathrm{~min}$ to chew a hole $2-4 \mathrm{~mm}$ in diameter through the calyces of Pavonia dasypetala from which it steals nectar (Roubik 1982).

\section{Indirect resistance}

Predators of nectar robbers may also serve to protect plants. For example, some plants produce extrafloral nectaries (nectar-secreting tissues located on leaves, stems, or external calyces of flowers) that attract ants that deter herbivores. Keeler (1977) found that ants attracted to the extrafloral nectaries of Ipomoea carnea also deterred carpenter bees from robbing flowers. Additional benefits of extrafloral nectaries are reviewed in detail in Rudgers and Gardener (2004, this Special Feature).

\section{Resistance Traits and Plant Defense}

Although traits that might confer resistance to nectar robbers have been identified, little is known about whether these traits actually defend plants against nectar robbers. Using Karban and Myers' (1989) classification, a defense trait not only must decrease the preference (or performance) of nectar robbers but also must increase plant fitness in the presence of robbers.

It might seem intuitive that traits that decrease nectar robbing should increase plant fitness; however, this need not be the case. For example, constitutive traits that provide a fairly constant and effective deterrence against robbers might incur both allocation costs (resource-based trade-offs between resistance and fitness) and ecological costs (trade-offs between resistance traits and interactions with other organisms, such as mutualists; Strauss et al. 2002). Moreover, plants may be able to compensate for damage to floral reproductive structures or loss of nectar by producing more flowers or by increasing nectar production rate (analogous to tolerance to herbivores; Strauss and Agrawal 1999). In cases in which robbers do not damage plant reproductive structures and pollinators are unaffected by the reduction of nectar due to robbing, a plant may gain no benefit in deterring robbers. Finally, recent theoretical studies suggest that mutualisms, such as those between plants and pollinators, can persist even in the presence of cheaters that have negative consequences on the mutualism (Morris et al. 2003).

Although traits conferring resistance to herbivores have been linked to plant fitness (reviewed in Marquis 1992), evidence that resistance to nectar robbers affects plant fitness is largely lacking. Only one study, to our knowledge, has measured the fitness consequences of a resistance trait to robbers. L. S. Adler and R. E. Irwin (unpublished manuscript) experimentally manipulated

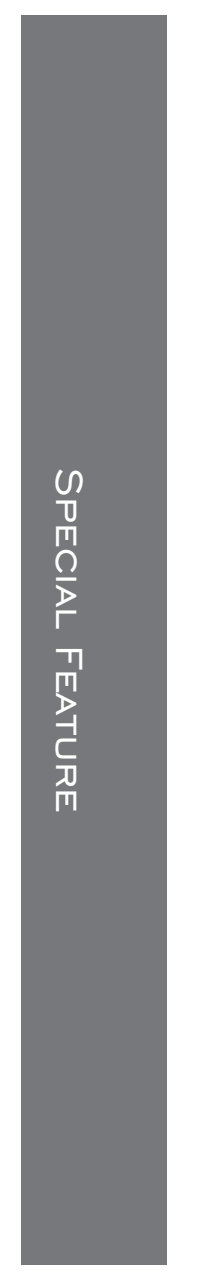


alkaloids in the nectar of Gelsemium sempervirens. Toxic nectar decreased male reproductive success because toxic nectar deterred pollinators as well as nectar robbers. More studies relating resistance traits against robbers to plant fitness are needed before any generalizations can be made.

\section{InduCED RESPONSES to NeCTAR Robbers}

If resistance traits against nectar robbers carry high allocation or ecological costs, induction of resistance upon damage is one way in which plants might lower such costs. Induced responses to herbivore damage are common (Karban and Baldwin 1997), and there is evidence for induced responses against exploitation in other kinds of mutualisms (e.g., Pellmyr and Huth 1994). However, induction has not been examined in association with robbers. Damage to floral tissue by nectar robbers may induce a variety of plant responses, such as increased secondary chemical production in floral tissues or nectar. Damage to petal tissue can induce secondary compounds to those same petals within hours (Euler and Baldwin 1996). Damage to tissue on one flower may induce secondary chemicals in all floral tissue on a plant or in nectar. For example, artificial damage to floral tissue of Nemophila menziesii decreased the preference of florivores for subsequent flowers produced on damaged plants compared to undamaged controls (A. C. McCall, personal communication). Because nectar robbers chew through floral tissue to obtain nectar, their damage is probably indistinguishable from that produced by florivores. Thus, nectar robbers could induce the production of secondary compounds in petals or nectar. Such a mechanism probably is not applicable to nectar thieves because they do not damage floral parts.

For induced responses against nectar robbers to be favored, however, the response must reduce subsequent attack by nectar robbers and must increase plant fitness in the presence of robbers. No studies have tackled induced responses to nectar robbers.

\section{Do Resistance Traits Against Robbers Benefit Plants? A Case Study}

Although a variety of traits might confer resistance to nectar robbers, we remain relatively ignorant of the fitness benefits associated with most of these traits, as well as their potential costs. Here we attempt to address this gap by examining the fitness benefits associated with one putative resistance trait, low sugar concentration in nectar (hereafter referred to as dilute nectar). We examined whether dilute nectar would deter nectarrobbing bees without deterring hummingbird pollinators, as proposed by Bolten and Feinsinger (1978), resulting in increased female fitness in a pollen-limited plant.

\section{Methods}

We studied the montane perennial herb Ipomopsis aggregata (Polemoniaceae), growing near the Rocky
Mountain Biological Laboratory (RMBL), elevation $2800 \mathrm{~m}$, in the Elk Mountains of central Colorado, USA. Around the RMBL, I. aggregata grows as a vegetative rosette for 2-7 years, flowers once, and dies (Waser and Price 1989). Therefore, lifetime reproduction of a plant can be measured in one flowering season. Ipomopsis aggregata flowers for $\sim 4-8$ weeks, producing numerous red, trumpet-shaped flowers. The flowers are hermaphroditic, self-incompatible, and rely primarily on Broad-tailed (Selasphorus platycercus) and Rufous Hummingbirds (S. rufus) for pollination.

The flowers of I. aggregata are robbed by a bumble bee, Bombus occidentalis. The bees chew a hole through the side of the corolla through which they remove all available nectar in a single visit. While robbing, the bees neither pollinate the plant nor damage the plants' reproductive or nectar-producing structures (R. E. Irwin, unpublished data). High levels of robbing ( $>80 \%$ of available flowers robbed) are common and reduce male and female plant reproduction by $50 \%$ (Irwin and Brody 2000), an indirect effect due to avoidance of robbed plants and flowers by hummingbird pollinators (Irwin and Brody 1998).

In 1998, we randomly chose 10 I. aggregata in each of four sites, each occupied by $>200$ flowering I. aggregata plants. All sites had similar slope and co-occurring flowering species and were within $2 \mathrm{~km}$ of each other. Throughout the flowering season, we estimated nectar robbing two times per week by counting the number of open flowers and the number of flowers with robber holes on each plant (as in Irwin and Maloof 2002). To our knowledge, in I. aggregata, no other organisms commonly steal nectar through the holes made by $B$. occidentalis. We estimated pollinator visitation two times per week using stigma pollen loads as indices. In I. aggregata, increased pollinator visitation results in increased pollen receipt (Engel and Irwin 2003). We measured sugar concentration (measured in percentage of sucrose equivalents) of nectar on an average of two bagged, unrobbed flowers per plant using a hand-held refractometer (Leica IFT40, Leica Microsystems, Buffalo, New York, USA). Because nectar concentration can vary daily and with weather conditions (Pleasants 1983), we only sampled sugar concentration at midday on sunny days at peak flowering for each plant. The variance in nectar concentration within plants $(2.88 \%)$ is significantly lower than the variance in nectar concentration among plants $(6.25 \%)\left(F_{\mathrm{S}}=2.17\right.$, df $=1,254, N=256$ plants, $P$ $<0.01$; R. E. Irwin and A. K. Brody, unpublished data). Therefore, measuring sugar concentration in two flowers per plant probably provided a reliable estimate of whole-plant concentration. When plants ceased blooming, we estimated female fitness as the total number of seeds produced per plant (hereafter referred to as plant fitness). Seed production and offspring recruitment are positively correlated for I. aggregata $(\mathrm{N}$. 

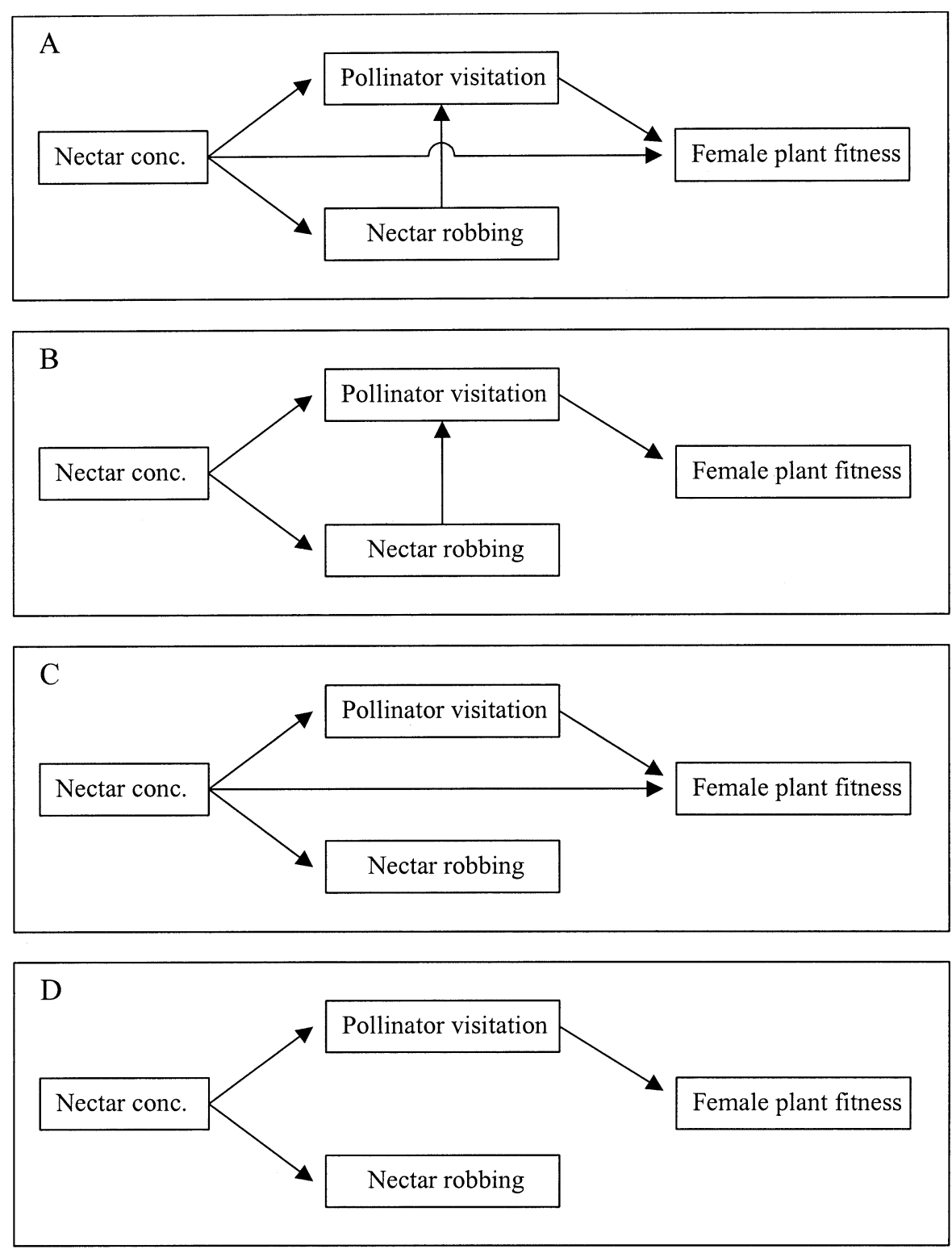

FIG. 1. Four competing path diagrams testing the direct and indirect effects of sugar concentration of nectar (nectar conc.) on pollinator visitation (estimated as pollen receipt to stigmas), nectar robbing, and plant fitness (estimated as seed set). In all models, there is unexplained variation $\left[\left(1-R^{2}\right)^{0.5}\right]$ associated with the measurement of pollinator visitation, nectar robbing, and seed set. See Methods for explanation of the models.

M. Waser, M. V. Price, A. K. Brody, and D. R. Campbell, unpublished data).

To examine whether dilute nectar deters robbing bees without deterring pollinating hummingbirds, we used path analysis combined with structural equation modeling (SEM; for a review see Mitchell [1993]) to compare four competing a priori hypotheses (Fig. 1). In all models, nectar concentration affects hummingbird and bumble bee preference, given that both birds and bees forage selectively on sugar rewards (reviewed in Proctor et al. 1996), and pollinator visitation directly affects female plant fitness (Campbell and Halama 1993). In
Model A (Fig. 1), dilute nectar directly affects plant fitness and indirectly affects plant fitness through changes in robber and pollinator foraging behavior. Although the physiology of nectar production in $I$. aggregata is unknown, to our knowledge, plants could produce dilute nectar by putting more water in the nectar or by putting less sugar in the nectar. Thus, the direct effect of producing dilute nectar on plant fitness could be negative if plants are water limited, or positive if sugar is costly. In Model B, all paths remain identical to those of Model A except that the path between dilute nectar and fitness is constrained to zero, assuming that 
TABLE 1. Observed correlations $(r)$ among sugar concentration in nectar, pollinator and nectarrobber visitation, and plant fitness.

\begin{tabular}{|c|c|c|c|}
\hline Variables & $\begin{array}{c}\text { Nectar } \\
\text { concentration }\end{array}$ & $\begin{array}{l}\text { Pollinator } \\
\text { visitation }\end{array}$ & Nectar robbing Plant fitness \\
\hline \multicolumn{4}{|l|}{ Nectar concentration } \\
\hline Pollinator visitation & -0.08 & & \\
\hline Nectar robbing & 0.45 & -0.61 & \\
\hline Plant fitness & -0.30 & 0.21 & -0.18 \\
\hline
\end{tabular}

dilute nectar has no direct allocation cost or benefit to plants. In Model C, all paths remain identical to those of Model A except that robbers have no indirect effect on plant fitness through pollinator behavior. Model C assumes that pollinators do not avoid robbed plants, which could occur if nectar is a limited resource at a landscape scale and pollinators become less selective among plants when nectar resources are limited (Carpenter 1979). In Model D, all paths remain identical to those of Model C except that the path between dilute nectar and fitness is constrained to zero. If dilute nectar confers resistance to nectar robbers, we expect that robbers will avoid plants with dilute nectar, resulting in increased pollinator visitation and enhanced plant fitness.

Ideally, in this study we would have controlled the genetic background in which nectar concentration was expressed by using a series of experimental crosses. However, this was not possible with a long-lived monocarpic plant. To compensate, we worked with plants in a variety of sites and thus minimized the likelihood that dilute nectar was spuriously correlated with other putative resistance traits (Strauss et al. 2002). To avoid the confounding influence of correlations between traits across sites, rather than among individuals within sites (the relevant hypothesis), we tested for homogeneity of the covariance structure of the variables across sites using PROC DISCRIM, option POOL $=$ TEST (SAS Version 8; SAS Institute 2001). We found no evidence to reject the null hypothesis of homogeneity of the covariance structure $\left(\chi^{2}=36.64\right.$, $P=0.18)$; therefore, we pooled the data across sites.

To compare the four models, we used SEM, which tests the fit of the correlation matrix of alternative path

TABLE 2. A comparison of alternative path diagrams (Fig. 1) using structural equation modeling (SEM).

\begin{tabular}{ccccc}
\hline \hline Model & \multicolumn{1}{c}{$\chi^{2}$} & df & $P \dagger$ & AIC $\ddagger$ \\
\hline A & 0.36 & 1 & 0.5490 & -1.64 \\
B & 3.11 & 2 & 0.2111 & -0.89 \\
C & 17.83 & 2 & 0.0001 & 13.83 \\
D & 20.58 & 3 & 0.0001 & 14.58 \\
\hline
\end{tabular}

$\dagger$ Significant $\chi^{2}$ values indicate that the models deviate significantly from the observed data.

$\ddagger$ Akaike's Information Criterion. models to the observed correlation matrix of the data (Table 1) using a goodness-of-fit statistic that has an approximate $\chi^{2}$ distribution. A nonsignificant $\chi^{2}$ value indicates that the expected correlations in the path diagram do not differ significantly from the observed correlations in the data, suggesting that the model provides a reasonable fit to the data. We also report Akaike's Information Criterion (AIC). AIC penalizes models with more parameters (i.e., a net effect of adding variables and paths; SAS Institute, personal communication). The model that minimizes AIC provides the most reasonable fit to the data. For the path diagram that provided the best fit to the observed data, we calculated direct effects (standardized partial regression coefficients), indirect effects, and significance levels. All statistical analyses were conducted in PROC CALIS (SAS Version 8; SAS Institute 2001).

\section{Results}

Neither Model A nor Model B differed significantly from the observed data (Table 2), suggesting that both models provided reliable fits to the data. To further compare the relative fit of Models A and B, we took the difference in their goodness-of-fit statistics and degrees of freedom (Mitchell 1993). We found a nonsignificant difference between Models A and B $\left(\chi^{2}=2.75\right.$, df $=1, P=0.1)$. Because Model A had a slightly lower AIC value than Model B, we retained Model A (Table 2, Fig. 2).

In Model A, plants with dilute nectar experienced significantly less robbing, suggesting that dilute nectar may confer resistance to nectar robbers. There was a positive relationship between nectar concentration and hummingbird visitation, but not statistically significant (Fig. 2). However, pollinators strongly avoided robbed plants (Fig. 2). Therefore, any benefits of dilute nectar are likely to be mediated through pollinator avoidance of robbed plants and not pollinator preference for dilute nectar, per se (Martínez del Rio et al. 2001).

Although pollinator visitation usually limits female fitness in I. aggregata (Campbell and Halama 1993), increased pollinator visitation explained relatively little of the variation in seed set in 1998 (Fig. 2). Amongyear variation in the degree to which plants are pollen limited is not uncommon. Pollen receipt to stigmas in 


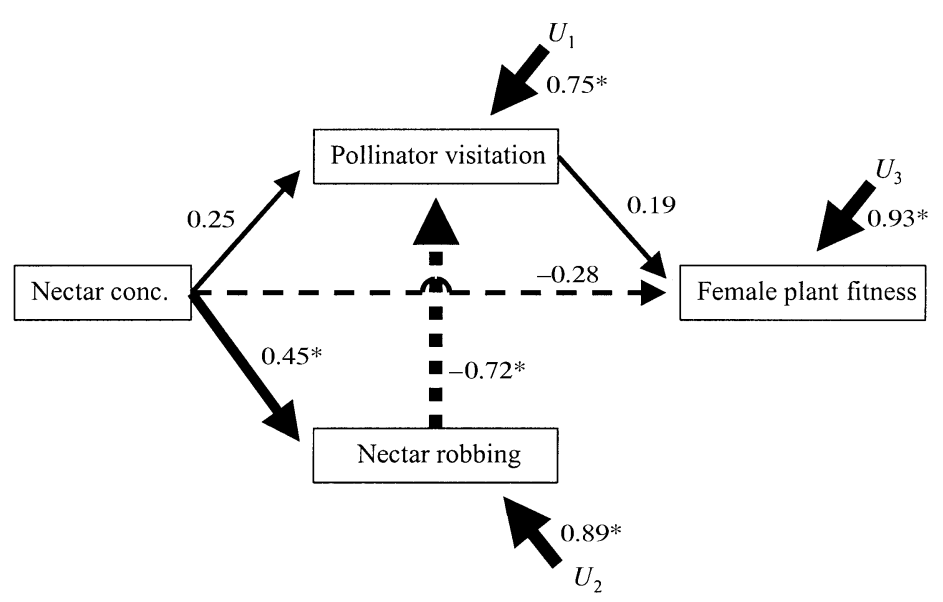

FIG. 2. Path diagram that provided the best fit to the observed correlation matrix (Table 1), identified using SEM (Table 2). Positive effects are indicated by solid lines, and negative effects by dashed lines. The widths of the arrows indicate the magnitude of the standardized path coefficients. Pathways significant at $P<0.05$ are denoted by an asterisk. The residual variables for pollinator visitation $\left(U_{1}\right)$, nectar robbing $\left(U_{2}\right)$, and seed set $\left(U_{3}\right)$ indicate unmeasured factors.

1998 was $>20 \%$ higher than in 2001 , another year in which we measured this response variable $\left(F_{1,72}=4.42\right.$, $P=0.039$; Engel and Irwin 2003), suggesting that seed set was not limited by pollen receipt in 1998, and/or that resources also limited seed production in the year of study (R. E. Irwin, unpublished data). Because the link between pollinator visitation and female fitness was weak, robbing had only a marginally negative effect on plant fitness mediated indirectly through the avoidance of robbed plants by pollinators.

Dilute nectar had a weak, nonsignificant direct fitness benefit to plants (Fig. 2). The marginal direct benefits of dilute nectar to plant fitness outweighed the indirect benefits through decreased robbing and increased pollination, probably because plants were only weakly pollen limited. In years with strong pollen limitation of seed set, the indirect benefits of dilute nectar on resistance to robbing might outweigh the direct benefits. This might be the case because of the strong links between robber avoidance of dilute nectar and pollinator avoidance of robbed plants. To further test this hypothesis, we need to experimentally manipulate nectar concentration in combination with resource availability and pollen limitation, measure subsequent levels of robbing, and assess male and female plant fitness.

\section{Conclusions and Avenues FOR FUtURE RESEARCH}

Nectar serves as an important reward, mediating interactions between plants and pollinators. Here we show that particular nectar traits may also confer resistance against nectar robbers. To understand the evolutionary ecology of nectar traits that provide resistance, we need to quantify their costs and benefits. For Ipomopsis aggregata, dilute nectar deters nectar-robbing bumble bees. Dilute nectar may also increase plant fitness in years of strong pollinator limitation of seed set, suggesting that nectar may play a dual role of reward and defense in some years.

A variety of questions must be addressed before we can fully understand the degree to which nectar traits defend plants against nectar robbers. We list three intriguing and challenging questions.

(1) Are there allocation and/or ecological costs associated with resistance to nectar robbers? - Theories of plant defense rely on the assumption that plants experience costs associated with resistance traits (McKey 1974). Otherwise, we would expect plants to be maximally resistant. Plants do incur both allocation and ecological costs associated with resistance to herbivores (recently reviewed in Strauss et al. 2002). However, almost nothing is known about costs of resistance to nectar robbing. Robbing levels vary widely both geographically and temporally (Irwin and Maloof 2002), and variability in robbing may constrain selection for resistance traits that are costly to produce. Given the crucial importance of both pollinators (Dodd et al. 1999, Grimaldi 1999) and herbivores (Becerra 1997, Farrell 1998) in shaping plant evolution and speciation, it is essential to integrate robbers, which could influence both plant secondary compounds and floral traits, into our conceptual framework of plant-animal interactions.

(2) Can plants tolerate the negative effects of nectar robbers?-Resistance represents just one strategy that plants use to cope with attack. Plants may also be able to tolerate the negative effects of robbing, incurring few, if any, fitness consequences as a result of damage. The negative effects of robbers may be tolerable if, for example, plants can produce enough nectar to feed all floral visitors. Tolerance to herbivory is common (Strauss and Agrawal 1999) and may represent an alternative or additional defensive mechanism to resistance (Fineblum and Rausher 1995, Mauricio et al. 
1997). No studies, to our knowledge, have addressed the degree to which tolerance mitigates the negative effects of robbing.

(3) Do genetic correlations among nectar-robber and herbivore resistance traits impact the evolutionary response of plants to simultaneous attack by multiple enemies?-Plant-robber interactions occur within a broader framework that includes other antagonists, including herbivores, florivores, and seed predators. The complexity of direct and indirect interactions among enemies and their shared host plants has long been recognized; however, our understanding of the ecological and evolutionary outcomes of multiple-species interactions is still in its infancy (e.g., Juenger and Bergelson 1998, Galen and Cuba 2001). Genetic correlations between resistance traits against herbivores and nectar robbers may constrain the degree to which plants can respond to any one selective agent. Moreover, natural enemies that share the same host plant may have non-additive effects on plant fitness, affecting the degree to which plants can coevolve with any one enemy.

\section{ACKNOWLEDGMENTS}

Thanks to A. Toth for help in the field, J. Bronstein, L. Burkle, A. McCall, J. Rudgers, and one anonymous reviewer for valuable comments on the manuscript, and A. Agrawal for help with organizing this Special Feature on Nectar Ecology. The Rocky Mountain Biological Laboratory provided a stimulating work environment. Field and laboratory work and travel for collaboration among the co-authors was supported by grants from the National Science Foundation (DEB9806501, DEB-0089643, DEB-0211480) and by funds from the University of Georgia.

\section{Literature Cited}

Adler, L. S. 2000. The ecological significance of toxic nectar. Oikos 91:409-420.

Adler, L. S., R. Karban, and S. Y. Strauss. 2001. Direct and indirect effects of alkaloids on plant fitness via herbivory and pollination. Ecology 82:2032-2044.

Agrawal, A. A., and R. Karban. 2000. Specificity of constitutive and induced resistance: pigment glands influence mites and caterpillars on cotton plants. Entomologia Experimentalis et Applicata 96:39-49.

Agrawal, A. A., C. Laforsch, and R. Tollrian. 1999. Transgenerational induction of defenses in animals and plants. Nature 401:60-63.

Armbruster, W. S. 1997. Exaptations link evolution of plantherbivore and plant-pollinator interactions: a phylogenetic inquiry. Ecology 78:1661-1672.

Baker, H. G. 1977. Non-sugar chemical constituents of nectar. Apidologie 8:349-356.

Baker, H. G., and I. Baker. 1982. Chemical constituents of nectar in relation to pollination mechanisms and phylogeny. Pages 131-171 in M. H. Nitecki, editor. Biochemical aspects of evolutionary biology. University of Chicago Press, Chicago, Illinois, USA.

Becerra, J. X. 1997. Insects on plants: macroevolutionary chemical trends in host use. Science 276:253-256.

Bolten, A. B., and P. Feinsinger. 1978. Why do hummingbird flowers secrete dilute nectar? Biotropica 10:307-309.

Brönmark, C., L. B. Pettersson, and P. A. Nilsson. 1999. Predator-induced defense in curcian carp. Pages 203-217 in R. Tollrian and C. D. Harvell, editors. The ecology and evolution of inducible defenses. Princeton University Press, Princeton, New Jersey, USA.
Bryant, J. P., J. Tuomi, and P. Niemala. 1988. Environmental constraint of constitutive and long-term inducible defenses in woody plants. Pages 367-389 in K. P. Springer, editor. Chemical mediation of coevolution. Academic Press, San Diego, California, USA.

Campbell, D. R., and K. J. Halama. 1993. Resource and pollen limitations to lifetime seed production in a natural plant population. Ecology 74:1043-1051.

Carpenter, F. L. 1979. Competition between hummingbirds and insects for nectar. American Zoologist 19:1105-1114.

Cipollini, M. L., and D. J. Levey. 1997. Secondary metabolites of fleshy vertebrate-dispersed fruits: adaptive hypotheses and implications for seed dispersal. American Naturalist 150:346-372.

Dodd, M. E., J. Silvertown, and M. W. Chase. 1999. Phylogenetic analysis of trait evolution and species diversity variation among angiosperm families. Evolution 53:732744.

Engel, E. C., and R. E. Irwin. 2003. Linking pollinator visitation rate and pollen receipt. American Journal of Botany 90:1612-1618.

Euler, M., and I. T. Baldwin. 1996. The chemistry of defense and apparency in the corollas of Nicotiana attenuata. Oecologia 107:102-112.

Farrell, B. D. 1998. "Inordinate fondness" explained: why are there so many beetles? Science 281:555-559.

Feeny, P. 1970. Seasonal changes in oak leaf tannins and nutrients as a cause of spring feeding by winter moth caterpillars. Ecology 51:103-111.

Fineblum, W. L., and M. D. Rausher. 1995. Tradeoff between resistance and tolerance to herbivore damage in a morning glory. Nature 377:517-520.

Galen, C. 1983. The effect of nectar-thieving ants on seedset in floral scent morphs of Polemonium viscosum. Oikos 41: 245-249.

Galen, C., and J. Cuba. 2001. Down the tube: pollinators, predators, and the evolution of flower shape in the alpine skypilot, Polemonium viscosum. Evolution 55:1963-1971.

Gardener, M. C., and M. P. Gillman. 2002. The taste of nectar-a neglected area of pollination ecology. Oikos 98: 552-557.

Grimaldi, D. 1999. The co-radiations of pollinating insects and angiosperms in the Cretaceous. Annals of the Missouri Botanical Garden 86:373-406.

Guerrant, E. O., and P. L. Fielder. 1981. Flower defenses against nectar-pilferage by ants. Biotropica 13(Supplemental):25-33.

Herrera, C. M. 1982. Defense of ripe fruit from pests: its significance in relation to plant-disperser interactions. American Naturalist 120:218-241.

Inouye, D. W. 1980. The terminology of floral larceny. Ecology 61:1251-1253.

Irwin, R. E., and A. K. Brody. 1998. Nectar robbing in Ipomopsis aggregata: effects on pollinator behavior and plant fitness. Oecologia 116:519-527.

Irwin, R. E., and A. K. Brody. 1999. Nectar-robbing bumble bees reduce the fitness of Ipomopsis aggregata (Polemoniaceae). Ecology 80:1703-1712.

Irwin, R. E., and A. K. Brody. 2000. Consequences of nectar robbing for realized male function in a hummingbird-pollinated plant. Ecology 81:2637-2643.

Irwin, R. E., A. K. Brody, and N. M. Waser. 2001. The impact of floral larceny on individuals, populations, and communities. Oecologia 129:161-168.

Irwin, R. E., and J. E. Maloof. 2002. Variation in nectar robbing over time, space, and species. Oecologia 133:525533.

Juenger, T., and J. Bergelson. 1997. Pollen and resource limitation of compensation to herbivory in scarlet gilia, Ipomopsis aggregata. Ecology 78:1684-1695. 
Juenger, T., and J. Bergelson. 1998. Pairwise versus diffuse natural selection and the multiple herbivores of scarlet gilia, Ipomopsis aggregata. Evolution 52:1583-1592.

Karban, R., and I. T. Baldwin. 1997. Induced responses to herbivory. University of Chicago Press, Chicago, Illinois, USA.

Karban, R., and J. H. Myers. 1989. Induced plant responses to herbivory. Annual Review of Ecology and Systematics 20:331-348.

Kearns, C. A., D. W. Inouye, and N. M. Waser. 1998. Endangered mutualisms: the conservation of plant-pollinator interactions. Annual Review of Ecology and Systematics 29:83-112.

Keeler, K. H. 1977. The extrafloral nectaries of Ipomoea carnea (Convolvulaceae). American Journal of Botany 64: 1182-1188.

Krischik, V. A., R. W. Goth, and P. Barbosa. 1991. Generalized plant defense: effects on multiple species. Oecologia 85:562-571.

Lara, C., and J. F. Ornelas. 2001. Preferential nectar robbing of flowers with long corollas: experimental studies of two hummingbird species visiting three plant species. Oecologia 128: $263-273$.

Maloof, J. E., and D. W. Inouye. 2000. Are nectar robbers cheaters or mutualists? Ecology 81:2651-2661.

Marquis, R. J. 1992. The selective impact of herbivores. Pages 301-325 in R. S. Fritz and E. L. Simms, editors. Plant resistance to herbivores and pathogens. University of Chicago Press, Chicago, Illinois, USA.

Martínez del Rio, C., J. E. Schondube, T. J. McWhorter, and L. G. Herrera. 2001. Intake responses in nectar feeding birds: digestive and metabolic causes, osmoregulatory consequences, and coevolutionary effects. American Zoologist 41:902-915.

Mauricio, R., M. D. Rausher, and D. S. Burdick. 1997. Variation in the defense strategies of plants: are resistance and tolerance mutually exclusive? Ecology 78:1301-1311.

McKey, D. 1974. Adaptive patterns in alkaloid physiology. American Naturalist 108:305-320.

Mitchell, R. J. 1993. Path analysis: pollination. Pages 211231 in S. M. Scheiner and J. Gurevitch, editors. Design and analysis of ecological experiments. Chapman and Hall, New York, New York, USA.

Morris, W. F., J. L. Bronstein, and W. G. Wilson. 2003. Threeway coexistence in obligate mutualist-exploiter interactions: the potential role of competition. American Naturalist 161: $860-875$.

Omer, A. D., J. Granett, R. Karban, and E. M. Villa. 2001. Chemically-induced resistance against multiple pests in cotton. International Journal of Pest Management 47:4954.

Painter, R. H. 1958. Resistance of plants to insects. Annual Review of Entomology 3:267-290.
Pellmyr, O., and C. J. Huth. 1994. Evolutionary stability of mutualism between yuccas and yucca moths. Nature 372: 257-260.

Pleasants, J. M. 1983. Nectar production in Ipomopsis aggregata (Polemoniaceae). American Journal of Botany 70: 1468-1475.

Proctor, M., P. Yeo, and A. Lack. 1996. The natural history of pollination. Timber Press, Portland, Oregon, USA.

Prŷs-Jones, O. E., and P. G. Willmer. 1992. The biology of alkaline nectar in the purple toothwort (Lathraea clandestina): ground level defenses. Biological Journal of the Linnean Society 45:373-388.

Pyke, G. H. 1991. What does it cost a plant to produce nectar? Nature 350:58-59.

Pyke, G. H., and N. M. Waser. 1981. The production of dilute nectars by hummingbird and honeyeater flowers. Biotropica 13:260-270.

Roubik, D. W. 1982. The ecological impact of nectar-robbing bees and pollinating hummingbirds on a tropical shrub. Ecology 63:354-360.

Rudgers, J. A., and M. C. Gardener. 2004. Extrafloral nectar as a resource mediating multispecies interactions. Ecology 85:1495-1502.

SAS Institute. 2001. SAS. Version 8. SAS Institute, Cary, North Carolina, USA.

Stephenson, A. G. 1981. Toxic nectar deters nectar thieves of Catalpa speciosa. American Midland Naturalist 105: 381-383.

Stephenson, A. G. 1982. Iridoid glycosides in the nectar of Catalpa speciosa are unpalatable to nectar thieves. Journal of Chemical Ecology 8:1025-1034.

Strauss, S. Y., and A. A. Agrawal. 1999. The ecology and evolution of plant tolerance to herbivory. Trends in Ecology and Evolution 14:179-185.

Strauss, S. Y., J. K. Conner, and S. L. Rush. 1996. Foliar herbivory affects floral characters and plant attractiveness to pollinators: implications for male and female plant fitness. American Naturalist 147:1098-1107.

Strauss, S. Y., R. E. Irwin, and V. Lambrix. 2004. Optimal defense theory and flower petal color predict variation in the secondary chemistry of wild radish. Journal of Ecology 92:132-141.

Strauss, S. Y., J. A. Rudgers, J. A. Lau, and R. E. Irwin. 2002. Direct and ecological costs of resistance to herbivory. Trends in Ecology and Evolution 17:278-285.

Tahvanainen, J. O., and R. B. Root. 1972. The influence of vegetational diversity on the population ecology of a specialized herbivore, Phyllotreta cruciferae (Coleoptera: Chrysomelidae). Oecologia 10:321-346.

Waser, N. M., and M. V. Price. 1989. Optimal outcrossing in Ipomopsis aggregata: seed set and offspring fitness. Evolution 43: 1097-1109.

Wootton, J. T., and I.-F. Sun. 1989. Bract liquid as a herbivore defense mechanism. Biotropica 22:155-159. 